\title{
Calculation and Influencing Factors of the Operating Efficiency of Chinese Airports under High-Quality Development
}

\author{
Meng Shang, ${ }^{1}$ Chunjie Jia $\mathbb{D}^{1}{ }^{1}$ Hui Li $\mathbb{D}^{2},{ }^{2}$ Yu Liu, ${ }^{1}$ and Junwei Cao ${ }^{3}$ \\ ${ }^{1}$ School of Flight, Anyang Institute of Technology, Anyang 455000, China \\ ${ }^{2}$ School of Management, Guangxi University for Nationalities, Nanning 530006, China \\ ${ }^{3}$ School of Digital Convergence Business, Yeungnam University, Gyeongsan, Republic of Korea \\ Correspondence should be addressed to Chunjie Jia; 20192052@ayit.edu.cn
}

Received 25 November 2021; Revised 13 December 2021; Accepted 14 December 2021; Published 6 January 2022

Academic Editor: Daqing Gong

Copyright ( $\odot 2022$ Meng Shang et al. This is an open access article distributed under the Creative Commons Attribution License, which permits unrestricted use, distribution, and reproduction in any medium, provided the original work is properly cited.

\begin{abstract}
Based on the cross-sectional data of 40 large-scale international airports in China in 2019, this paper introduced natural and social factors into the calculation of airport operating efficiency and constructed a BCC-SFA-BCC-Tobit 4-stage analysis framework. Combining with the connotation of the "green, smart, humane, and safe" airport high-quality development, the paper applied the Tobit model to quantitatively analyze the influencing factors of the operating efficiency of airports, and the research shows that (1) the overall operating efficiency of the study airports is 0.734 ; in terms of the region, the operating efficiency of airports located in southwest and northwest regions is greatly affected by natural factors, while the operating efficiency of airports located in North China is mostly affected by social factors. (2) Under the perspective of human-earth relationship, the impact of natural factors on the operating efficiency of airports is greater than that of social factors, wherein PM2.5 and relative humidity have negative impact, while the actual foreign capital utilization of the city and domestic and foreign tourists have positive impact. (3) The regression results of the Tobit model indicate that green, smart, and safe indicators can promote the high-quality development of airports, while the humane indicator restrains the high-quality development of airports.
\end{abstract}

\section{Introduction}

High-quality development is not only a basic feature of the economic development in the new era, but also the development trend of civil aviation industry. In the future, more attention will be paid to the high-quality development concepts of civil aviation safety, greenness, openness, sharing, and efficiency. In the transportation industry, the airport is an important source of development in the civil aviation industry. In 2019, the total transportation turnover and passenger volume of China's civil aviation transportation industry had, respectively, increased by $11.0 \%$ and $10.7 \%$ compared with the data by the end of the "Twelfth Five-Year Plan." Under the great pressure of the increasing transportation business demand, sometimes, airports would take simple and straightforward measures to cope with their difficulty such as expanding existing airports or constructing new ones to increase the capacity of the airports; however, the excessively advanced planning and construction of airports can easily cause a large number of idle seats, aprons, and other input resources, resulting in waste of resources. In this context, scientifically measuring the operating efficiency of the airports in China and evaluating the influencing factors of the high-quality development of Chinese airports are meaningful research works for realizing the sustainable development of airports.

For the research topic of airport operating efficiency, field scholars in the world have done a lot of works; for example, Doganis et al. [1] introduced the DEA method to airport performance evaluation and analysis for the first time; since then, DEA has been widely applied to airport efficiency evaluation. Gillen and Lall [2] used a DEA model to measure the operating efficiency of 21 airports in the United States and analyzed a few factors that can affect airport efficiency, including the operation productivity indicators, the environmental variables, and the management 
variables. Afterwards, the research on airport operating efficiency gets deeper; scholars have further expanded the DEA model and used various DEA models such as superefficiency DEA [3], undesired output DEA [4], and window DEA and network DEA [5] to study the operating efficiency of airports. However, a disadvantage of the DEA model is that it cannot eliminate the impact of environmental factors and random errors on the efficiency of the decision-making units, and this would cause a large difference between the calculation results and the actual situation; in view of this defect, Fried et al. [6] proposed a three-stage improvement model and used the SFA equation to eliminate environmental factors (external variables that can affect the efficiency of airport operations) and statistical errors to recalculate the efficiency value. The three-stage DEA model is widely used in studies concerning airport operating efficiency [7], port operating efficiency [8], urban green development efficiency, energy utilization efficiency, etc. After carefully reviewing and analyzing the existing literatures, it is found that scholars tend to consider more about social and economic factors such as the per capita GDP, degree of openness, investment in technological innovation, and social welfare, and they rarely involved the natural environment factors. However, in fact, natural environmental factors such as rainfall, haze weather, and wind levels in the area where the airport is located will affect flight scheduling and actual operations; different natural environment factors have different impacts on airport operating efficiency, which would result in certain deviations when evaluating the operating efficiency of airports.

Hence, to solve the deficiencies of the researches listed above, this paper combined the features of the influencing factors of airport operating efficiency and introduced natural environment factors and social factors to expand the traditional DEA model. Natural factors include two secondary indicators of air quality and meteorological conditions, and social factors include four secondary indicators of economic development level, industrial structure, degree of external development, and degree of competition; then, using a threestage DEA model, this paper discussed the operating efficiency of 40 large international airports in China and quantitatively analyzed and compared the impact of these two kinds of uncontrollable factors on airport operating efficiency, which is the main innovation of this paper. At last, according to the airport construction guidance of "green, smart, humane, and safe," this paper employed a Tobit regression model to analyze the key factors driving the highquality development of airports.

The rest of this paper is structured as follows: Section 1 reviews existing literatures on airport operating efficiency; Section 2 gives a brief introduction to the DEA method and the Tobit regression analysis method; Section 3 is about the design of the research, including the selection of variables, the selection of samples, and the explanation of data source; Section 4 measures and calculates the airport operating efficiency and analyzes the factors that can drive the highquality development of airport operating efficiency; Section 5 summarizes this paper and proposes management enlightenment.

\section{Literature Review}

2.1. Airport Operating Efficiency. DEA is a mature method for evaluating the efficiency of airport operations; DEA, as well as methods improved based on DEA, is widely applied in various industries. Pels et al. [9] compared and analyzed the efficiency of European airports. Fernandes and Pacheco [10] evaluated the transportation efficiency and passenger utilization efficiency of 35 airports in Brazil to determine the time for each airport to expand its capacity to maintain a service standard currently required by passengers. Sarkis and Talluri [11] compared and analyzed the operating efficiency of 44 airports in the United States over the past five years and made improvements from the perspective of four types of resource input: airport operating costs, number of airport employees, gates, and runways. Based on network DEA, Lozano et al. [12] considered two undesired outputs of the number of delayed flights and the cumulative flight delays and compared and analyzed the differences of these two methods in efficiency measurement and calculation. With environmental factors and statistical errors taken into consideration, Cui et al. [13] used the three-stage DEA and Bootstrap DEA to measure the utilization efficiency of coal resources in China. Fuentes et al. [14] combined the threestage DEA with the superefficiency DEA to eliminate the impact of situational variables and measured the teaching efficiency in the process of higher education. Wen et al. [15] evaluated the carbon emission efficiency of China's industrial sector based on information entropy and an improved DEA cross model. Ha et al. [16] and Button et al. [17], respectively, used the DEA-Tobit model to evaluate the efficiency of small-scale tourist airports and the efficiency of airports in Northeast Asia. The literature review reveals that the application of three-stage DEA is relatively mature; it can effectively eliminate the impact of environmental factors on the operating efficiency of airports; therefore, this paper decided to use the three-stage DEA method to evaluate the airport operating efficiency. Moreover, previous studies are mostly about the operating efficiency of airports in one country or in different countries, but they did not classify these airports. Therefore, this paper took 40 large-scale international airports with the service level over 10 million passengers as subjects to evaluate their operating efficiency; then, the Tobit model was employed to search for factors that can affect the operating efficiency of these airports. This paper aims to provide a useful reference for promoting the high-quality development of Chinese airports.

2.2. Indicators of Airport Operating Efficiency. The selection of input indicators, output indicators, and airport environmental factor indicators is extremely important for the measurement of the impact on airport operating efficiency. According to literature review, different scholars have slightly different choices of indicators. In terms of input, Gillen and Lall [2], D'Alfonso et al. [18], and Fragoudaki et al. [19] summarized and found that the most frequently used indicators are the number of runways, number of boarding gates, area of terminal buildings, number of 
parking spaces, number of airport employees, operating expenses, number of aprons, etc. In terms of output, the most frequently used indicators are the number of plane takeoffs and landings, number of passengers, and cargo and mail throughput [4]. Some scholars also took financial indicators such as operating income and noncommercial income as output indicators [20]. Overall, scholars at home and abroad have similar choices of input and output indicators, so based on the research of previous scholars, in this paper, 3 input indicators and 3 output indicators had been selected.

Regarding environmental indicators that can affect airport operating efficiency, Ha et al. [16] took the ownership property of airports, competition between airports, traffic composition, and the geographic location of airports as explanatory variables, while scholar Huynh et al. [21] took the airports' competitiveness, user attractiveness, and ownership property as explanatory variables. The abovementioned literature review also suggests that, among existing studies, few have involved environmental variables, or the selection is not comprehensive or systematic enough. Therefore, this paper divided the external environmental variables into natural environment factors and social factors and used three-stage DEA to evaluate the operating efficiency of 40 large-scale international airports in China.

\section{Research Methods}

3.1. Three-Stage DEA. The three-stage DEA was proposed by scholar Fried [6]. Compared with traditional DEA, it can effectively eliminate the impact of environmental variables and random errors on efficiency measurement, and the analysis results are more accurate. At the same time, by combining it with Tobit regression, the operating efficiency of major Chinese airports could be evaluated objectively, and useful suggestions could be provided for the high-quality development of Chinese airports.

The first stage: construction of the DEA-BCC model. The DEA model in the first stage adopted the BCC model with variable returns to scale and decomposed the technical efficiency (TE) into scale efficiency (SE) and pure efficiency (PE). The supposed BCC model is as follows:

$$
\begin{aligned}
& \operatorname{Min}\left[\theta-\varepsilon\left(\sum_{j=1}^{m} s^{-}+\sum_{j=1}^{m} s^{+}\right)\right]=V d(\varepsilon) \\
& \text { s.t }\left\{\begin{array}{l}
\sum_{j=1}^{n} \lambda_{j} x_{j}+s^{-}=\theta x_{j}, \\
\sum_{j=1}^{n} \lambda_{j} y_{j}-s^{+}=y_{j}, \\
\sum_{j=1}^{n} y_{j}=1, \lambda_{j} \geq 0, j=1,2, \ldots, n s^{-} \geq 0, s^{+} \geq 0,
\end{array}\right.
\end{aligned}
$$

where $\mathrm{s}^{-}$and $\mathrm{s}^{+}$are slack variables; $\varepsilon$ is a non-Archimedean infinitesimal quantity. When $\theta<1$, the decision unit is called DEA invalid; when $\theta=1$, and $s^{-}=0, s^{+}=0$, the decision unit is called DEA valid; when $\theta=1, s^{-} \neq 0$ or $s^{+} \neq 0$, the decision unit is called weakly DEA valid.

The second stage: SFA regression. Introduce SFA regression, unify the external environment of the decisionmaking units, calculate the difference in the operating efficiency of the airports before and after considering the natural environment factors and social factors, and quantitatively analyze their impact on the operating efficiency of the airports. It is supposed that, in the DEA model, there are $n$ decision-making units, $m$ input factors, and $p$ external factors; then, for each decision-making unit, there is

$$
s_{i k}=f_{i}\left(z_{k} ; \beta_{i}\right)+v_{i k}+u_{i k},
$$

where $i=1,2,3, \ldots, m, s_{i k}$ is the slack variable of the $i$-th input of the $k$-th decision-making unit in the model; $z_{k}$ contains $p$ external factors; $\beta_{i}$ is the parameter to be estimated corresponding to the external variables in function $f_{i}$; usually it is assumed that $f_{i}=\beta_{0}+\beta_{1} z_{1 k}+\cdots+\beta_{p} z_{p k} ; v_{i k}+$ $u_{i k}$ represents the mixed error term in SFA regression; $v_{i k}$ is a random interference term that obeys the normal distribution; $u_{i k}$ is a management inefficiency term that obeys the seminormal distribution.

The third stage: adjusting the initial input value according to the SFA regression results, the adjustment formula is

$X_{i k}^{A}=X_{i k}+\left[\max f_{i}\left(z_{k} ; \beta_{i}\right)-f_{i}\left(z_{k} ; \beta\right)\right]+\left[\max \left(v_{k i}\right)-v_{k i}\right]$,

where $i=1,2,3, \ldots, m, k=1,2,3, \ldots, n, X_{i k}$ represents the initial value of the $i$-th input in the $k$-th decision-making unit, $X_{i k}^{A}$ represents the adjustment value, and $\beta_{i}$ represents the estimated value of the environmental variable parameter.

3.2. Tobit Regression. In the high-quality development stage of the airports, the main influencing factors of airport operating efficiency are another key point in this paper, so we took the evaluation score of the airport efficiency in the third stage as the dependent variable to evaluate the influencing factors of airport operating efficiency. Tobit regression [22] is a commonly used model for processing censored data regression. This paper used Eviews to perform Tobit regression analysis. The structural equation of the Tobit model is

$$
Y_{i}=\beta_{0}+\beta^{T} X_{i}+\mu_{i},
$$

where $i=1,2,3, \ldots, m, Y_{i}$ is the evaluation score of the operating efficiency of the $i$-th airport; it is taken as the dependent variable; $X_{i}$ is the specific control variable of the airport, such as the airport security and the airport intelligence. $\beta^{T}$ is an unknown parameter, $\mu_{i} \sim N\left(0, \sigma^{2}\right)$; when the Tobit model is evaluated by the maximum likelihood method, $\beta^{T}$ and $\sigma^{2}$ are consistent estimates. $\beta^{0}$ represents the intercept term, and $\mu_{i}$ represents the disturbance term that obeys the mean value of 0 . 


\section{Design of the Research}

4.1. Selection of Variables. In this paper, when calculating the airport operating efficiency, the airport resource consumption was taken as the input factor, the relevant economic output was taken as the output factor, and the natural environment factors and social factors affecting airport operating efficiency were regarded as uncontrollable factors. Then, based on relevant studies at home and abroad, with the availability and completeness of the data taken into account, an evaluation indicator system was built for assessing the operating efficiency of large-scale airports in China, as shown in Table 1.

The Chinese airport operating efficiency evaluation indicator system contains four parts. The selection of input and output indicators was the same as previous studies, such as Pacagnella Junior et al. [23], Ahn and Min [4]; therefore, this paper did not discuss the details; here, we only explain the uncontrollable factors.

Banker believes that the environmental factors affecting DEA efficiency measurement include controllable and uncontrollable factors. Drawing on the human-earth relationship system proposed by Zhou Liang in his study on urban green development efficiency, this paper divided uncontrollable factors into two aspects: natural factors and social factors. Overall, the economy of eastern coastal areas in China develops better than that of the western regions, and there are large differences in the natural environment conditions between the north and the south areas, and these differences are prone to cause imbalance in the measurement of airport operating efficiency.

About the natural environment factors: the selection of natural environment factors was divided into two phases: primary selection and secondary selection. During primary selection, refer to the literature statement of Zhou et al. [24], Zhang et al. [25], and Zhou et al. [26]; six indicators including precipitation, annual sunshine hours, and PM2.5 were initially selected to represent the natural environment conditions of the city where the airport is located. Then, the six indicators were subject to correlation test, and the results that larger correlation test values have been discarded are shown in Table 2. Annual sunshine hours, annual average humidity, average temperature, and PM2.5 showed strong correlations. In order to minimize the impact of unfavorable factors and improve the accuracy of the results, two indicators of annual sunshine hours and average temperature had been discarded during the selection process.

About the social factors: scholars have done a lot of research on the social elements that affect the airport operating efficiency, but the selection of indicators lacks a unified standard. In view of this problem, this paper referred to existing studies and the actual conditions of the study airports and initially determined 8 indicators (of 4 aspects of economic development, industrial structure, degree of openness, and degree of competition) for correlation test. As shown in Table 3, the total GDP of the city, the per capita GDP, and the import and export trade volume of the city showed strong correlations; the proportion of secondary industries and the proportion of tertiary industries showed strong correlation; in order to minimize the impact of unfavorable factors and improve the accuracy of the results, three indicators of GDP, the proportion of secondary industries, and the import and export trade volume of the city had been discarded during the selection process.

4.2. Sample Selection and Data Source. In this study, 40 largescale airports in China were taken as the basic research units; the research data are cross-sectional data of year 2019, taking into account the influence of various influencing factors on the final result; the deviation of the data is standardized. which covers 4 aspects. (1) Airports. The airport input and output data come from the statistics published by the Civil Aviation Administration of China and the official websites of each airport. (2) Natural environment. The data of PM2.5, relative humidity, precipitation, temperature, and wind scale mainly come from the statistical information published on the China Meteorological Data Website (http://data.cma.cn/ ) and the official website of China Meteorological Administration (http://www.cma.gov.cn/). (3) Social environment. Data of social environment factors such as the per capita GDP, the import and export trade volume of the city, and the actual foreign capital utilization of the city mainly come from the China Statistical Yearbook 2020, the China City Statistical Yearbook 2020 of each city, and the statistical data released by the city's statistical bureau. (4) Airport highquality development indicators. Wherein the investment in energy conservation and emission reduction was estimated based on the investment data of the Civil Aviation Development Fund in 2019 and each airport's transportation volume proportion, the airport $\mathrm{CO}_{2}$ emissions mainly include carbon emissions from airports and terminal buildings. The calculation of the carbon emissions of airports was based on the ICAO standard emission model; the Python software was used to get key information of each airport, such as the flights and models; then, according to the fuel consumption of the airplane engine at each stage published on the International Civil Aviation Organization (ICAO) website, the carbon emissions of each complete LTO cycle were calculated. The carbon emissions of the airport terminal buildings were calculated according to the Guidelines for Energy Efficiency Evaluation of Civil Airport Terminals (MH/T5112-2016). The data of other statistical indicators come from documents such as the 2019 Domestic Civil Aviation Airport Development Report and the 2019 Civil Aviation Airport Service Quality Evaluation Report.

\section{Calculation of Airport Operating Efficiency and Analysis of Influencing Factors}

5.1. First-Stage Calculation Results. The first stage adopted an input-oriented BCC model [23]; the DEAP2.1 software was used to calculate the input-output efficiency of 40 airports and the total slack value of input indicators, as shown in Table 4.

The efficiency value of each airport has been measured according to DEA software; overall, the average values of TE, $\mathrm{PE}$, and $\mathrm{SE}$ are $0.791,0.909$, and 0.82 , respectively, indicating 
TABLE 1: The Chinese airport operating efficiency evaluation indicator system.

\begin{tabular}{|c|c|c|c|c|}
\hline Item & Category & $\begin{array}{l}\text { Description of the } \\
\text { indicator }\end{array}$ & Specific indicator & $\begin{array}{l}\text { Source of the } \\
\text { indicator }\end{array}$ \\
\hline \multirow{3}{*}{ Input factor } & \multirow{3}{*}{ Resource input } & $\begin{array}{l}\text { Input in terminal } \\
\text { buildings }\end{array}$ & Area of terminal buildings & Junior et al. [5] \\
\hline & & Input in parking bays & Number of parking bays & $\begin{array}{l}\text { Pacagnella junior } \\
\text { et al. [23] }\end{array}$ \\
\hline & & Input in runways & Area of runways & Liu [7] \\
\hline \multirow{2}{*}{ Output factor } & \multirow{2}{*}{$\begin{array}{c}\text { Economic } \\
\text { output }\end{array}$} & Throughput & $\begin{array}{c}\text { Passenger throughput } \\
\text { Cargo and mail throughput }\end{array}$ & $\begin{array}{c}\text { Ahn and min [4] } \\
\text { Liu [7] }\end{array}$ \\
\hline & & $\begin{array}{l}\text { Number of plane } \\
\text { takeoffs and landings }\end{array}$ & Number of plane takeoffs and landings & Ahn and $\min [4]$ \\
\hline \multirow{14}{*}{$\begin{array}{l}\text { Uncontrollable } \\
\text { factor }\end{array}$} & \multirow{6}{*}{ environment } & \multirow{3}{*}{ Air quality } & PM2.5 & $\begin{array}{l}\text { Zhou et al. [24]; } \\
\text { Zhang et al. [25] }\end{array}$ \\
\hline & & & Relative humidity & $\begin{array}{l}\text { Zhou et al. [24]; } \\
\text { Zhang et al. [25] }\end{array}$ \\
\hline & & & Precipitation & Zhang et al. [25] \\
\hline & & \multirow{3}{*}{ Climate conditions } & Temperature & Zhou et al. [26] \\
\hline & & & Wind scale & Zhou et al. [26] \\
\hline & & & Annual sunshine hours & Zhou et al. [26] \\
\hline & \multirow{8}{*}{$\begin{array}{c}\text { Social } \\
\text { environment }\end{array}$} & Economic development & Total GDP of the city & Ma et al. [27]; \\
\hline & & level & Per capital GDP & Ma et al. [27]; \\
\hline & & \multirow[t]{3}{*}{ Industrial structure } & Proportion of secondary industries & $\begin{array}{l}\text { Ma et al. [27]; } \\
\text { Huang et al. [28] }\end{array}$ \\
\hline & & & Proportion of tertiary industries & Huang et al. [28] \\
\hline & & & Import and export trade volume of the city & Huang et al. [28] \\
\hline & & \multirow[t]{2}{*}{ Degree of openness } & Actual foreign capital utilization of the city & Huang et al. [28] \\
\hline & & & Domestic and foreign tourists & Huang et al. [28] \\
\hline & & Degree of competition & $\begin{array}{c}\text { Civil aviation passenger traffic volume/(Railway } \\
\text { passenger traffic volume + civil aviation passenger } \\
\text { traffic volume) }\end{array}$ & Fan et al. [29] \\
\hline
\end{tabular}

TABLE 2: Correlation test of natural environment factors of Chinese airports.

\begin{tabular}{|c|c|c|c|c|c|c|}
\hline Parameter & Annual sunshine hours & PM2.5 & Precipitation & Relative humidity & Temperature & Wind scale \\
\hline Annual sunshine hours & 1.000 & & & & & \\
\hline PM2.5 & 0.198 & 1.000 & & & & \\
\hline Precipitation & -0.632 & -0.580 & 1.000 & & & \\
\hline Relative humidity & -0.819 & -0.544 & 0.799 & 1.000 & & \\
\hline Temperature & -0.602 & -0.477 & 0.737 & 0.729 & 1.000 & \\
\hline Wind scale & 0.479 & -0.116 & -0.240 & -0.273 & -0.291 & 1.000 \\
\hline
\end{tabular}

that the overall efficiency of large-scale airports in China is good. To thoroughly study the difference in the operating efficiency of airports of different scales, according to scale cluster analysis results, the 40 airports were divided into three classes: I, II, and III (10-20 million, 20-40 million, and more than 40 million). The average TE values of the three classes of airports are $0.733,0.844$, and 0.817 , respectively; the difference is not significant; however, in terms of SE, the average values of the three are $0.762,0.958$, and 0.913 , respectively; the difference is significant; this indicates that, compared with Class-I airports, Class-II and Class-III airports have obvious advantages in economies of scale, and after the scale reaches a certain level, the SE will decrease gradually.

5.2. Second-Stage SFA Regression. This paper attempts to explore the influencing factors of the operating efficiency of Chinese airports from two angles of natural environment and social factors. Refer to the two-stage measurement method of Pacagnella Junior et al. [23]; in SFA regression, the impact of natural environmental factors and social factors the airport operating efficiency was eliminated one by one, and the results obtained after analyzed by the Frontier4.1 software are given in Table 5 .

According to the fitting results of the two models, the airport operating efficiency is affected by both natural and social factors. For the 40 major airports in China, among the natural environment factors, the two indicators of PM2.5 and relative humidity both passed the $99 \%$ significance level test, the other two indicators of wind scale and precipitation had not passed the significance test, and their impact on airport operating efficiency is not obvious. Among the social factors, the coefficients of the impact of per capita GDP and the proportion of tertiary industries on terminal buildings, parking bays, and runways are all negative numbers, indicating that the increase in per capita GDP and the proportion 
TABLE 3: Correlation test of social factors of Chinese airports.

\begin{tabular}{|c|c|c|c|c|c|c|c|c|}
\hline Parameter & $\begin{array}{l}\text { City } \\
\text { GDP }\end{array}$ & $\begin{array}{l}\text { Per } \\
\text { capita } \\
\text { GPD }\end{array}$ & $\begin{array}{l}\text { Proportion of } \\
\text { secondary } \\
\text { industries }\end{array}$ & $\begin{array}{c}\text { Proportion of } \\
\text { tertiary } \\
\text { industries }\end{array}$ & $\begin{array}{l}\text { Import and } \\
\text { export trade } \\
\text { volume of the } \\
\text { city (in } 100 \\
\text { million yuan) }\end{array}$ & $\begin{array}{l}\text { Actual foreign } \\
\text { capital } \\
\text { utilization of } \\
\text { the city }\end{array}$ & $\begin{array}{l}\text { Domestic } \\
\text { and foreign } \\
\text { tourists }\end{array}$ & $\begin{array}{l}\text { Competition } \\
\text { degree of civil } \\
\text { aviation }\end{array}$ \\
\hline GDP & 1 & & & & & & & \\
\hline Per capita GPD & 0.63 & 1 & & & & & & \\
\hline $\begin{array}{l}\text { Proportion of } \\
\text { secondary } \\
\text { industries }\end{array}$ & -0.196 & 0.097 & 1 & & & & & \\
\hline $\begin{array}{l}\text { Proportion of } \\
\text { tertiary industries }\end{array}$ & 0.36 & 0.112 & -0.936 & 1 & & & & \\
\hline $\begin{array}{l}\text { Import and } \\
\text { export trade } \\
\text { volume of the city }\end{array}$ & 0.825 & 0.504 & -0.207 & 0.354 & 1 & & & \\
\hline $\begin{array}{l}\text { Actual foreign } \\
\text { capital utilization } \\
\text { of the city }\end{array}$ & 0.252 & 0.348 & 0.218 & -0.131 & 0.119 & 1 & & \\
\hline $\begin{array}{l}\text { Domestic and } \\
\text { foreign tourists }\end{array}$ & 0.629 & 0.08 & -0.035 & 0.068 & 0.422 & 0.282 & 1 & \\
\hline $\begin{array}{l}\text { Competition } \\
\text { degree of civil } \\
\text { aviation }\end{array}$ & -0.204 & -0.019 & -0.157 & 0.194 & -0.047 & -0.263 & -0.26 & 1 \\
\hline
\end{tabular}

of tertiary industries would cause excessive input in airport terminals, parking bays, and runways and lower the operating efficiency, and this can reflect from another angle that the advanced investment can cause resource wastes.

5.3. Third-Stage Estimated Results. The adjusted input values after two SFA regressions were, respectively, substituted into the BCC model to calculate the operating efficiency of the study airports; the results are listed in Table 6. In order to measure the deviation of the two SFA regressions to the model calculation results, the deviation degree is defined as deviation degree $=$ first stage airport operating efficiency value - adjusted efficiency value, deviation degree $\epsilon(-1,1)$. If the deviation degree is greater than zero, it means that the operating efficiency of an airport is overestimated; if the deviation degree is less than zero, it means that the operating efficiency of the airport is underestimated.

According to Table 6, we can know the following:

(1) After excluding natural environment factors and social factors, the absolute values of deviation are 3.381 and 2.659, respectively, indicating that the impact of natural environment factors is greater than that of social factors. After excluding natural environmental factors, the average value of airport operating efficiency changed from 0.791 to 0.793 ; the change is little, and this is because China's vast territory and diverse climate can cover various environment types, which has neutralized the regional differences. After excluding the social environment, the average value of airport operating efficiency dropped from 0.793 to 0.734 , and the decrease is significant, indicating that the airport operating system is a part of the big urban social environment, and the development of the social environment has a positive impact on the operating efficiency of the airports.

(2) From the perspective of natural environment factors, the spatial heterogeneity of airports has different impact on airport operating efficiency. Among the 40 airports, the efficiency of 8 airports has been overestimated, such as airports in Hohhot, Lanzhou, and Xining in northwest China; their deviation degrees are $0.297,0.219$, and 0.209 , respectively, indicating that these airports have most of the weather factors required for efficient operation, such as clear weather, high visibility, and few thunderstorms. Therefore, the construction of the airport must make full use of the advantages of the natural environment to increase throughput such as the number of takeoffs and landings. In addition, the efficiency of 8 airports has been underestimated, such as the airports in Changsha, Chengdu, and Chongqing; their deviation degrees are $-0.253,-0.208$, and -0.121 , respectively, indicating that the airports are often affected by unfavorable weather factors that are not conducive to flight takeoff, such as thunderstorm, haze, and low visibility. Therefore, in the construction of the airport, it is necessary to fully consider the design of the runway direction, the arrangement of the flight plan, etc. to avoid the adverse effects of the natural environment. Moreover, the operating efficiency of the other 24 airports has not changed much.

(3) From the perspective of social factors, after adjustment, the average TE has dropped from 0.793 to 0.734; the change is not much. In terms of deviation degree, the deviation degrees of 36 airports are positive, and the deviation degrees of 4 airports are 
TABLE 4: First-stage calculation results of operating efficiency of Chinese airports.

\begin{tabular}{|c|c|c|c|c|c|}
\hline No. & DMU & $\mathrm{TE}$ & PTE & SE & Return to scale \\
\hline 1 & Beijing/Capital airport & 1 & 1 & 1 & - \\
\hline 2 & Shanghai/Pudong airport & 1 & 1 & 1 & - \\
\hline 3 & Guangzhou/Baiyun airport & 0.859 & 0.878 & 0.977 & Drs \\
\hline 4 & Chengdu/Shuangliu airport & 0.766 & 1 & 0.766 & Drs \\
\hline 5 & Shenzhen/Bao'an airport & 0.957 & 1 & 0.957 & Drs \\
\hline 6 & Kunming/Changshui airport & 0.884 & 1 & 0.884 & Drs \\
\hline 7 & Xi'an/Xianyang airport & 0.882 & 1 & 0.882 & Drs \\
\hline 8 & Shanghai/Hongqiao airport & 0.792 & 0.895 & 0.885 & Drs \\
\hline 9 & Chongqing/Jiangbei airport & 0.468 & 0.547 & 0.854 & Drs \\
\hline 10 & Hangzhou/Xiaoshan airport & 0.841 & 0.903 & 0.931 & Drs \\
\hline 11 & Nanjing/Lukou airport & 0.522 & 0.565 & 0.924 & Drs \\
\hline 12 & Zhengzhou/Xinzheng airport & 0.517 & 0.522 & 0.991 & Drs \\
\hline 13 & Xiamen/Gaoqi airport & 1 & 1 & 1 & - \\
\hline 14 & Wuhan/Tianhe airport & 0.52 & 0.55 & 0.946 & Drs \\
\hline 15 & Changsha/Huanghua airport & 0.71 & 0.809 & 0.878 & Drs \\
\hline 16 & Qingdao/Liuting airport & 1 & 1 & 1 & - \\
\hline 17 & Haikou/Meilan airport & 0.883 & 0.927 & 0.953 & Irs \\
\hline 18 & Urumchi/Diwopu airport & 0.888 & 0.919 & 0.966 & Irs \\
\hline 19 & Tianjin/Binhai airport & 0.815 & 0.861 & 0.946 & Drs \\
\hline 20 & Guiyang/Longdongbao airport & 1 & 1 & 1 & - \\
\hline 21 & Harbin/Taiping airport & 0.847 & 1 & 0.847 & Irs \\
\hline 22 & Shenyang/Taoxian airport & 0.903 & 0.915 & 0.987 & Drs \\
\hline 23 & Sanya/Fenghuang airport & 0.845 & 0.857 & 0.985 & Drs \\
\hline 24 & Dalian/Zhoushuizi airport & 1 & 1 & 1 & - \\
\hline 25 & Jinan/Yaoqiang airport & 1 & 1 & 1 & - \\
\hline 26 & Nanning/Wuxu airport & 0.665 & 1 & 0.665 & Irs \\
\hline 27 & Lanzhou/Zhongchuan airport & 0.949 & 0.954 & 0.995 & Irs \\
\hline 28 & Fuzhou/Changle airport & 0.63 & 1 & 0.63 & Irs \\
\hline 29 & Taiyuan/Wusu airport & 0.876 & 0.922 & 0.95 & Irs \\
\hline 30 & Changchun/Longjia airport & 0.606 & 1 & 0.606 & Irs \\
\hline 31 & Nanchang/Changbei airport & 0.667 & 0.772 & 0.864 & Irs \\
\hline 32 & Hohhot/Baita airport & 1 & 1 & 1 & - \\
\hline 33 & Ningbo/Lishe airport & 0.475 & 0.758 & 0.626 & Irs \\
\hline 34 & Wenzhou/Longwan airport & 0.547 & 1 & 0.547 & Irs \\
\hline 35 & Zhuhai/Jinwan airport & 1 & 1 & 1 & - \\
\hline 36 & Hefei/Xiinqiao airport & 0.938 & 1 & 0.938 & Irs \\
\hline 37 & Shijiazhuang/Zhengding airport & 0.49 & 0.941 & 0.521 & Irs \\
\hline 38 & Yinchuan/Hedong airport & 0.527 & 0.897 & 0.588 & Irs \\
\hline 39 & Yantai/Penglai airport & 0.696 & 0.977 & 0.713 & Irs \\
\hline 40 & Xining/Caojiapu airport & 0.665 & 1 & 0.665 & Irs \\
\hline \multicolumn{2}{|c|}{ Average value of the samples } & 0.791 & 0.909 & 0.82 & \\
\hline
\end{tabular}

negative, indicating that the overall operating efficiency of airports has been overestimated; that is, overall speaking, the impact of social factors on airport operating efficiency is positive. Among them, the efficiency value of Urumqi airport has dropped by as much as 0.242 ; its efficiency has been obviously overestimated. Analysis of the second stage showed that, in 2019, the number of tourist visits in Urumqi was only 2.489 million, and the airports in Taiyuan and Hefei were also affected by this. In contrast, for airports with a large number of domestic and foreign tourists, their efficiency generally increased, such that the deviation degrees of the efficiency values of airports in Chongqing, Wuhan, and Chengdu are $-0.051,-0.027$, and -0.016 , respectively, and the efficiency values have been generally underestimated.
(4) From the perspective of the scale of airports, for Class I, II, and III airports, the changes in SE are obvious, and the deviation degrees are 0.106, 0.079, and 0.008 , respectively. As the scale of the airport grows, the change in SE that is affected by social factors gets smaller. In terms of the airport location regions, the operating efficiency of airports located in southwest and northwest regions is greatly affected by natural environment factors, while the operating efficiency of airports located in North China is greatly affected by social factors.

5.4. Analysis of Driving Factors of Airport Operating Efficiency under High-Quality Development. Combining with the "Four Characteristics Airport Development Guidelines" (MH/T 5049-2020) issued by the Civil Aviation 
TABLE 5: Second-stage SFA regression results.

\begin{tabular}{|c|c|c|c|}
\hline Parameter & Terminal building & Parking bay & Runway \\
\hline Constant term & $-30.635^{* * *}(-30.37)$ & $-79.873^{* * *}(-79.9)$ & $-288.955^{* * *}(-25.42)$ \\
\hline PM2.5 & $0.268^{* * *}(6.58)$ & $0.483^{* *}(2.55)$ & $2.093^{* * *}(3.42)$ \\
\hline Relative humidity & $0.187^{* * *}(4.84)$ & $0.697^{* * *}(3.69)$ & $2.476^{* * *}(4.46)$ \\
\hline Wind scale & $1.404^{*}(1.625)$ & $-1.589 *(-1.72)$ & $-2.766(-0.69)$ \\
\hline Precipitation & $0.003^{* * *}(5.946)$ & $0.005(0.763)$ & $0.007(0.35)$ \\
\hline Sigma-square & $288.913^{* * *}(288.9)$ & $1078.39^{* * *}(1078.39)$ & $10362.462^{* * *}(10362.5)$ \\
\hline Gamma & $1.000^{* * *}(5799366.6)$ & $1.000^{* * *}(220479.43)$ & 1.000 \\
\hline Log value & -137.128 & -169.39 & -214.24178 \\
\hline LR value & 28.778 & 16.93127 & 17.735919 \\
\hline Constant term & $2.708^{*}(1.72)$ & $35.48827^{* * *}(40.05)$ & $74.04051^{* * *}(22.23)$ \\
\hline Actual foreign capital utilization of the city & $0.012^{* * *}(3.91)$ & $-0.01998^{* * *}(-9.83)$ & $0.102589^{*}(1.8)$ \\
\hline Per capita GPD & $-0.00004^{* * *}(-5.14)$ & $-0.0000085(-0.21)$ & $-0.00037^{* * *}(-2.56)$ \\
\hline Domestic and foreign tourists & $0.00016^{* * *}(3.78)$ & $0.000111^{* *}(1.97)$ & $0.001821^{* * *}(3.86)$ \\
\hline Proportion of tertiary industries & $-8.0911^{* * *}(-9.3)$ & $-58.971^{* * *}(-18.35)$ & $-206.899^{* * *}(-76.28)$ \\
\hline Competition degree of civil aviation & $4.086(1.01)$ & $-5.47656(-1.45)$ & $80.27351^{* * *}(15.7)$ \\
\hline Sigma-square & $242.528^{* * *}(188.9)$ & $1014.437^{* * *}(873.73)$ & $6659.749^{* * *}(6659.5)$ \\
\hline Gamma & $1^{* * *}(1264365.6)$ & $1^{* * *}(169122.5)$ & $1^{* * *}(203176.42)$ \\
\hline Log value & -132.51894 & -169.327 & -208.391 \\
\hline LR value & 31.04520 & 15.36687 & 13.02205 \\
\hline
\end{tabular}

Note. $(1)^{* * *},{ }^{* *}$, and ${ }^{*}$, respectively, represent that the term is significant at the levels of $1 \%, 5 \%$, and $10 \%$; (2) the value in brackets is the $P$ value.

Administration of China, in this paper, the 4 airport highquality development concepts of "green, smart, humane, and safe" were taken as first-level indicators; after initial screening, 9 second-level indicators were chosen to construct an indicator system for airport high-quality development, as shown in Table 7. Then, with the airport operating efficiency of the third stage as the explained variable, a Tobit regression model was constructed.

Indicator selection. About the green indicator, a green airport is an environment-friendly airport that can realize resource conservation and low-carbon operation throughout its entire life cycle; under this first-level indicator, two second-level indicators of investment in energy conservation and emission reduction and per capita $\mathrm{CO}_{2}$ emission of the airport had been selected. About the smart indicator, a smart airport is an airport that can realize full connection of all production factors, data sharing, efficient collaboration, and intelligent operation. The on-time departure rate and average delay time of departure of the airport are comprehensive manifestations of an airport's intelligence and coordination level; therefore, this paper chose the on-time departure rate and average delay time of departure as the second-level indicators under the first-level smart indicator. About the humane indicator, the construction of a humane airport is based on two aspects: cultural manifestation and humanistic care. The service system is the top priority for the construction of a humane airport; it is the manifestation of humanistic care in service behaviors and service products. Therefore, the airport service quality score and the airport complaint rate were selected as second-level indicators under the humane indicator. About the safe indicator, the construction of a safe airport pays close attention to basic requirements of civil aviation safety such as air defense safety, public safety, operational safety, and fire safety, among which the operational safety and air defense safety are the top priorities. Therefore, the major accident rate for per million flights and the transportation incident rate for per million flights were selected as explanatory variables.

Considering that there are many explanatory variables, correlation test and indicator screening were carried out to ensure the robustness of Tobit regression. The indicator correlation results are shown in Table 8. The correlation coefficients between the number of air defense security accidents investigated and handled and the $\mathrm{CO}_{2}$ emissions and transportation incident rate for per million flights reached 0.788 and 0.702 , respectively, and the values of the major accident rate for per million flights of each study airport were all 0 . Therefore, the two variables of the number of air defense security accidents investigated and handled and the major accident rate for per million flights were excluded, and the final form of Tobit regression is

$$
\begin{aligned}
\mathrm{AOE}_{i}= & \beta_{0}+\beta_{1} \ln (\mathrm{EC})+\beta_{2} \ln (\mathrm{CE}) \\
& +\beta_{3} \ln (\mathrm{OTP})+\beta_{4} \ln (\mathrm{DT})+\beta_{5} \ln (\mathrm{SQ}) \\
& +\beta_{6} \ln (\mathrm{CR})+\beta_{7} \ln (\mathrm{TAS})+\varepsilon,
\end{aligned}
$$

where $\mathrm{AOE}_{i}$ represents the operating efficiency value of the $i$-th airport, $\beta_{0}$ is a constant term, $\beta_{i}$ is the coefficient to be determined, and $\varepsilon$ is random error. Tobit regression results are shown in Table 9.

Tobit regression results showed that:

In terms of the green indicator, per capita $\mathrm{CO}_{2}$ emission is significantly negatively correlated with airport operating efficiency, while the impact of the investment in energy conservation and emission reduction on airport operating efficiency is not obvious. The smaller the per capita $\mathrm{CO}_{2}$ emission, the better the airport has done in low-carbon construction and optimizing the quality of air traffic operation. For example, Tianjin Binhai International Airport have added more than 200 new energy vehicles and completed more than 30 An APU alternative facility project in 2019; these low-carbon construction measures can reduce 
TABle 6: Third-stage operating efficiency of major Chinese airports and deviations.

\begin{tabular}{|c|c|c|c|c|c|c|}
\hline DMU no. & Location region & First stage & After SFA1 & After SFA2 & Deviation degree 1 & Deviation degree 2 \\
\hline 1 & North China & 1 & 1 & 1 & 0 & 0 \\
\hline 2 & East China & 1 & 1 & 1 & 0 & 0 \\
\hline 3 & Central and Southern China & 0.859 & 0.949 & 0.914 & -0.09 & 0.035 \\
\hline 4 & Southwest & 0.766 & 0.974 & 0.99 & -0.208 & -0.016 \\
\hline 5 & Central and Southern China & 0.957 & 1 & 0.925 & -0.043 & 0.075 \\
\hline 6 & Southwest & 0.884 & 1 & 1 & -0.116 & 0 \\
\hline 7 & Northwest & 0.882 & 1 & 1 & -0.118 & 0 \\
\hline 8 & East China & 0.792 & 0.909 & 0.888 & -0.117 & 0.021 \\
\hline 9 & Southwest & 0.468 & 0.589 & 0.64 & -0.121 & -0.051 \\
\hline 10 & East China & 0.841 & 0.942 & 0.856 & -0.101 & 0.086 \\
\hline 11 & East China & 0.522 & 0.601 & 0.596 & -0.079 & 0.005 \\
\hline 12 & Central and Southern China & 0.517 & 0.571 & 0.573 & -0.054 & -0.002 \\
\hline 13 & East China & 1 & 1 & 0.926 & 0 & 0.074 \\
\hline 14 & Central and Southern China & 0.52 & 0.655 & 0.682 & -0.135 & -0.027 \\
\hline 15 & Central and Southern China & 0.71 & 0.963 & 0.899 & -0.253 & 0.064 \\
\hline 16 & East China & 1 & 1 & 0.974 & 0 & 0.026 \\
\hline 17 & Central and Southern China & 0.883 & 0.886 & 0.738 & -0.003 & 0.148 \\
\hline 18 & Northwest & 0.888 & 0.909 & 0.667 & -0.021 & 0.242 \\
\hline 19 & North China & 0.815 & 0.82 & 0.754 & -0.005 & 0.066 \\
\hline 20 & Southwest & 1 & 1 & 0.954 & 0 & 0.046 \\
\hline 21 & Northeast & 0.847 & 0.811 & 0.664 & 0.036 & 0.147 \\
\hline 22 & Northeast & 0.903 & 0.868 & 0.797 & 0.035 & 0.071 \\
\hline 23 & Central and Southern China & 0.845 & 0.658 & 0.574 & 0.187 & 0.084 \\
\hline 24 & Northeast & 1 & 0.873 & 0.86 & 0.127 & 0.013 \\
\hline 25 & East China & 1 & 0.943 & 0.818 & 0.057 & 0.125 \\
\hline 26 & Central and Southern China & 0.665 & 0.699 & 0.575 & -0.034 & 0.124 \\
\hline 27 & Northwest & 0.949 & 0.73 & 0.656 & 0.219 & 0.074 \\
\hline 28 & East China & 0.63 & 0.588 & 0.485 & 0.042 & 0.103 \\
\hline 29 & North China & 0.876 & 0.788 & 0.624 & 0.088 & 0.164 \\
\hline 30 & Northeast & 0.606 & 0.495 & 0.482 & 0.111 & 0.013 \\
\hline 31 & East China & 0.667 & 0.748 & 0.684 & -0.081 & 0.064 \\
\hline 32 & North China & 1 & 0.703 & 0.564 & 0.297 & 0.139 \\
\hline 33 & East China & 0.475 & 0.53 & 0.515 & -0.055 & 0.015 \\
\hline 34 & East China & 0.547 & 0.554 & 0.522 & -0.007 & 0.032 \\
\hline 35 & Central and Southern China & 1 & 1 & 0.922 & 0 & 0.078 \\
\hline 36 & East China & 0.938 & 1 & 0.834 & -0.062 & 0.166 \\
\hline 37 & North China & 0.49 & 0.524 & 0.425 & -0.034 & 0.099 \\
\hline 38 & Northwest & 0.527 & 0.393 & 0.389 & 0.134 & 0.004 \\
\hline 39 & East China & 0.696 & 0.594 & 0.524 & 0.102 & 0.07 \\
\hline 40 & Northwest & 0.665 & 0.456 & 0.366 & 0.209 & 0.09 \\
\hline Mean & & 0.791 & 0.793 & 0.734 & - & - \\
\hline \multirow{8}{*}{ Sum of absolute values } & & - & - & - & 3.381 & 2.659 \\
\hline & Northeast & 0.839 & 0.762 & 0.701 & 0.077 & 0.061 \\
\hline & North China & 0.836 & 0.767 & 0.673 & 0.069 & 0.094 \\
\hline & East China & 0.778 & 0.800 & 0.740 & -0.023 & 0.061 \\
\hline & Northwest & 0.782 & 0.698 & 0.616 & 0.085 & 0.082 \\
\hline & Southwest & 0.779 & 0.891 & 0.896 & -0.111 & -0.005 \\
\hline & Central and Southern China & 0.773 & 0.820 & 0.756 & -0.047 & 0.064 \\
\hline & Mean & 0.791 & 0.793 & 0.731 & - & - \\
\hline
\end{tabular}

$\mathrm{CO} 2$ emissions while shortening the turnaround time of aircraft at the airport, and thereby improving the airport operating efficiency. The impact of the investment in energy conservation and emission reduction on airport operating efficiency is positive, but not particularly significant. This may be related to the hysteretic nature of the efficiency conversion of investment in energy conservation and emission reduction, or it may be due to the reason that the investment in energy conservation and emission reduction of the airport is not in place. Judging from the calculation results, Nanjing Lukou Airport, Wuhan Tianhe Airport, and Zhengzhou Xinzheng Airport have invested a lot in energy conservation and emission reduction; however, their operating efficiency is relatively low.

In terms of the smart indicator, the on-time departure rate is significantly positively correlated with airport operating efficiency. The on-time departure rate of an airport is a comprehensive manifestation of the hi-tech application, 
TABLE 7: Chinese airport high-quality development indicator system.

\begin{tabular}{|c|c|c|c|}
\hline Item & Name of the explained variable & Abbreviation & Indicator and its unit \\
\hline \multirow[t]{2}{*}{ Green } & $\begin{array}{l}\text { Investment in energy conservation and emission } \\
\text { reduction }\end{array}$ & $\mathrm{LN}(\mathrm{EC})$ & $\begin{array}{c}\text { Input expenses of energy conservation and emission } \\
\text { reduction (10,000 yuan) }\end{array}$ \\
\hline & $\mathrm{CO}_{2}$ emissions per capita & $\mathrm{LN}(\mathrm{CE})$ & $\mathrm{CO}_{2}$ emissions per capita(ton) \\
\hline \multirow{2}{*}{ Smart } & Collaborative and intelligent operation efficiency & OTP & On-time departure rate $(\%)$ \\
\hline & of the airport & LN(DT) & Average delay time of departure (min) \\
\hline Humane & Airport service & $\begin{array}{l}\mathrm{LN}(\mathrm{SQ}) \\
\mathrm{CR}\end{array}$ & $\begin{array}{l}\text { Airport service quality score } \\
\text { Airport complaint rate }(\%)\end{array}$ \\
\hline \multirow{2}{*}{ Safe } & Operational safety & $\begin{array}{c}\text { MA } \\
\text { LN(TAS) }\end{array}$ & \multirow{2}{*}{$\begin{array}{c}\text { Major accident rate for per million flights (\%) } \\
\text { Transportation incident rate for per million flights (\%) } \\
\text { Number of air defense security accidents investigated and } \\
\text { handled (case) }\end{array}$} \\
\hline & Air defense security & $\mathrm{LN}(\mathrm{ADA})$ & \\
\hline
\end{tabular}

TABLE 8: Correlation test of explanatory variables.

\begin{tabular}{|c|c|c|c|c|c|c|c|c|c|}
\hline Parameter & EC & $\mathrm{CE}$ & OTP & $\mathrm{DT}$ & SQ & $\mathrm{CR}$ & MA & TAS & $\mathrm{ADA}$ \\
\hline $\mathrm{EC}$ & 1.000 & & & & & & & & \\
\hline $\mathrm{CE}$ & 0.514 & 1.000 & & & & & & & \\
\hline OTP & 0.435 & 0.511 & 1.000 & & & & & & \\
\hline DT & -0.125 & 0.057 & -0.646 & 1.000 & & & & & \\
\hline SQ & -0.154 & 0.091 & -0.008 & -0.209 & 1.000 & & & & \\
\hline $\mathrm{CR}$ & -0.237 & -0.532 & -0.181 & -0.315 & -0.017 & 1.000 & & & \\
\hline MA & & & & & & & 1.000 & & \\
\hline TAS & 0.450 & 0.777 & 0.434 & 0.140 & 0.032 & -0.524 & & 1.000 & \\
\hline $\mathrm{ADA}$ & 0.462 & 0.788 & 0.564 & 0.094 & -0.132 & -0.554 & & 0.702 & 1.000 \\
\hline
\end{tabular}

TABLE 9: Tobit regression results.

\begin{tabular}{lccc}
\hline Parameter & Coefficient & Z statistics & Significance \\
\hline EC & 0.0249 & 1.139 & - \\
CE & -0.4179 & -3.136 & $* * *$ \\
OTP & 1.0656 & 2.592 & $* * *$ \\
DT & 0.3789 & 1.678 & $*$ \\
SQ & -0.4933 & -0.675 & - \\
CR & 0.0045 & 0.1515 & - \\
TAS & -0.5631 & -2.2458 & $*$ \\
Constant term & 7.790 & 1.657 & $* *$ \\
\hline
\end{tabular}

Note. $(1)^{* * *},{ }^{* *}$, and ${ }^{*}$, respectively, represent that the term is significant at the levels of $1 \%, 5 \%$, and $10 \%$; (2) the value in brackets is the $P$ value.

informatization construction, and production and business coordination of the airport; the higher the on-time departure rate, the higher the operating efficiency of the airport. For example, the on-time departure rates of Xi'an Xianyang Airport, Kunming Changshui Airport, and Chengdu Shuangliu Airport are all above $78 \%$, and their operating efficiency all reaches 1 . The positive correlation between the average delay time of departure and airport operating efficiency is not significant. This result is not in line with the expectations, and this may be because that the average delay of departure can only reflect the average delay time and cannot reflect the number of flight delays, and this may result in greater contingencies in statistical data.

In terms of the humane indicator, the service quality score is negatively correlated with airport operating efficiency, and the airport complaint rate is positively correlated with airport operating efficiency. These results are inconsistent with expectations; this may be due to the airports' excessive attention to the passengers' process experience; they shorten the security check time, airplane waiting time, and boarding time as much as possible, and at the same time, they fully consider the different needs of passengers and reduce the rate of airport complaints; however, these have also caused excessive input in airport terminals and parking bays, thereby affecting the airport operating efficiency.

In terms of the safe indicator, the transportation incident rate for per million flights is significantly negatively correlated with airport operating efficiency. The higher the transportation incident rate, the poorer abilities of the airport in preventing aviation risks and in operating the business smoothly; especially when emergency occurs, it can delay the airport system and affect its stable and orderly operation, thereby affecting the airport operating efficiency.

\section{Conclusion}

Based on the cross-sectional data of 40 major large-scale airports in China in 2019, this paper introduced natural 
environment and social factors into the calculation of airport operating efficiency, quantitatively analyzed the impact of uncontrollable factors on airport operating efficiency, and constructed an airport high-quality development indicator system based on four airport high-quality development concepts of "green, smart, humane, and safe"; then, this paper employed Tobit regression to analyze the factors affecting the airport's high-quality development and drew the following conclusions.

(1) From the perspective of human-earth relationship, the impact of natural environment factors on the operating efficiency of airports is greater than that of social factors; therefore, the airport organizations should pay attention to not only the social factors, but also the natural environment factors; they should effectively utilize favorable natural environment factors and avoid unfavorable natural environment factors, thereby improving their own operating efficiency.

(2) For airports located in different regions, the impact of natural environment and social factors varies greatly; among the natural environment factors, PM2.5 and relative humidity have a significant impact on airport operating efficiency, while the impact of temperature and wind scale is not obvious. Among the social factors, the actual foreign capital utilization of the airport and the domestic and foreign tourists are the core driving factors of airport operating efficiency.

(3) Tobit regression results show that the 3 indicators of green indicator, smart indicator, and safe indicator can promote the high-quality development of airports, while the humane indicator inhibits the highquality development of airports. Therefore, when airports are making efforts to improve their service quality, they must fully consider the resource input in terminal buildings, parking bays, and personnel and try to avoid excessive resource input.

Enlightenment and suggestion: first of all, airport managers should not lay emphasis only on the first stage airport operating efficiency, but also on the third stage airport operating efficiency. This is because the traditional DEA generally ignores the impact of managerial factors and statistical errors. Second, the increase in per capita GDP and the proportion of tertiary industries will cause excessive investment in terminal buildings, parking bays, and runways, thereby lowering the operating efficiency. Therefore, airport managers should improve airport management and planning levels to adapt to the expanding production scale, improve the technical efficiency of airport operations, and avoid the waste of resources caused by advanced investment. Third, after excluding the natural environment and social factors, the operating efficiency of some airports changed significantly. Airports should adopt different measures to improve their operating efficiency according to their own environmental conditions. For example, the Urumqi city is a hub connecting Asia and Europe, and it has abundant tourism resources, so the Urumqi airport could improve its operating efficiency by attracting tourists and expanding investment in import and export trades. However, for airports in southwestern regions such as Chengdu and Chongqing, their operating efficiency is greatly affected by their natural environment, so methods such as adjusting flight route arrangements and improving weather forecast accuracy could be adopted to avoid the adverse impact of external natural environment and improve their operating efficiency. At last, for the high-quality development of airports, safety is the top priority, and it is significantly negatively correlated with airport operating efficiency. In terms of humane passenger services, it is necessary for the airports to be realistic and not to blindly pursue face-saving projects and result in resource wastes.

The limitations of this study are as follows: first, the selected decision-making units are all large-scale airports in China; middle- and small-sized airports have not been involved in the study; second, the data used in this study are the cross-sectional data of 2019; therefore, it cannot well reflect the time series changes in the operating efficiency of airports in China. In the future, the selection scope of decision-making units will be extended to domestic airports of all scales; the data of recent 10 years will be included to study the temporal and spatial evolution characteristics of the operating efficiency of Chinese airports, and these are possible research attempts in our future works.

\section{Data Availability}

The data used to support the findings of this study are available from the corresponding author upon request.

\section{Conflicts of Interest}

The authors declare that they have no conflicts of interest.

\section{Acknowledgments}

This work was supported by the (1) Henan Province Philosophy and Social Science Planning Project (grant number: 2021CJJ122); (2) the Science and Technology Development Project of Henan Province in 2021 (Soft Science Research) (grant number: 212400410251); (3) The R\&D and Promotion Key Program of Anyang in 2020 (grant number: 2020-256); and (4) the Development Program for University Key Teacher of Henan Province (grant number: 2020GGJS233).

\section{References}

[1] R. S. Doganis, A. Graham, and A. Lobbenberg, "The economic performance of European airports," Journal of Air Transport Management, vol. 3, no. 2, p. 207, 1995.

[2] D. Gillen and A. Lall, "Developing measures of airport productivity and performance: an application of data envelopment analysis," Transportation Research Part E: Logistics and Transportation Review, vol. 33, no. 4, pp. 261-273, 1997.

[3] M.-M. Yu, "Assessment of airport performance using the SBM-NDEA model," Omega, vol. 38, no. 6, pp. 440-452, 2010.

[4] Y.-H. Ahn and H. Min, "Evaluating the multi-period operating efficiency of international airports using data 
envelopment analysis and the Malmquist productivity index," Journal of Air Transport Management, vol. 39, pp. 12-22, 2014.

[5] A. C. P. Junior, P. S. Hollaender, G. V. Mazzanati, and W. W. Bortolotto, "Efficiency drivers of international airports: a worldwide benchmarking study," Journal of Air Transport Management, vol. 90, Article ID 101960, 2021.

[6] H. O. Fried, C. K. Lovell, S. S. Schmidt, and S. Yaisawarng, "Accounting for environmental effects and statistical noise in data envelopment analysis," Journal of Productivity Analysis, vol. 17, no. 1, pp. 157-174, 2002.

[7] D. Liu, "Evaluating the multi-period efficiency of East Asia airport companies," Journal of Air Transport Management, vol. 59, pp. 71-82, 2017.

[8] Y. Han, C. Long, Z. Geng, and K. Zhang, "Carbon emission analysis and evaluation of industrial departments in China: an improved environmental DEA cross model based on information entropy," Journal of Environmental Management, vol. 205, pp. 298-307, 2018.

[9] E. Pels, P. Nijkamp, and P. Rietveld, "Relative efficiency of European airports," Transport Policy, vol. 8, no. 3, pp. 183-192, 2001.

[10] E. Fernandes and R. R. Pacheco, "Efficient use of airport capacity," Transportation Research Part A: Policy and Practice, vol. 36, no. 3, pp. 225-238, 2002.

[11] J. Sarkis and S. Talluri, "Performance based clustering for benchmarking of US airports," Transportation Research Part A: Policy and Practice, vol. 38, no. 5, pp. 329-346, 2004.

[12] S. Lozano, E. Gutiérrez, and P. Moreno, "Network DEA approach to airports performance assessment considering undesirable outputs," Applied Mathematical Modelling, vol. 37, no. 4, pp. 1665-1676, 2013.

[13] Y. Cui, G. Huang, and Z. Yin, "Estimating regional coal resource efficiency in China using three-stage DEA and bootstrap DEA models," International Journal of Mining Science and Technology, vol. 25, no. 5, pp. 861-864, 2015.

[14] R. Fuentes, B. Fuster, and A. Lillo-Bañuls, "A three-stage DEA model to evaluate learning-teaching technical efficiency: key performance indicators and contextual variables," Expert Systems with Applications, vol. 48, pp. 89-99, 2016.

[15] J. Wen, H. Wang, F. Chen, and R. Yu, "Research on environmental efficiency and TFP of Beijing areas under the constraint of energy-saving and emission reduction," Ecological Indicators, vol. 84, pp. 235-243, 2018.

[16] H.-K. Ha, Y. Wan, Y. Yoshida, and A. Zhang, "Airline market structure and airport efficiency: evidence from major Northeast Asian airports," Journal of Air Transport Management, vol. 33, pp. 32-42, 2013.

[17] K. Button, T. Kramberger, K. Grobin, and B. Rosi, "A note on the effects of the number of low-cost airlines on small tourist airports' efficiencies," Journal of Air Transport Management, vol. 72, pp. 92-97, 2018.

[18] T. D'Alfonso, C. Daraio, and A. Nastasi, "Competition and efficiency in the Italian airport system: new insights from a conditional nonparametric Frontier analysis," Transportation Research Part E: Logistics and Transportation Review, vol. 80, pp. 20-38, 2015.

[19] A. Fragoudaki, D. Giokas, and K. Glyptou, "Efficiency and productivity changes in Greek airports during the crisis years 2010-2014," Journal of Air Transport Management, vol. 57, pp. 306-315, 2016.

[20] B. S. Unsal, M. Aroney, and B. Mohammed, "Size versus efficiency: a case study of US commercial carriers," Transportation Research Procedia, vol. 48, pp. 93-106, 2020.
[21] T. M. Huynh, G. Kim, and H.-K. Ha, "Comparative analysis of efficiency for major Southeast Asia airports: a two-stage approach," Journal of Air Transport Management, vol. 89, Article ID 101898, 2020.

[22] J. Tobin, "Estimation of relationships for limited dependent variables," Econometrica: Journal of the Econometric Society, vol. 26, no. 1, pp. 24-36, 1958.

[23] A. C. Pacagnella Junior, P. S. Hollaender, G. V. Mazzanati, and W. W. Bortoletto, "Infrastructure and flight consolidation efficiency of public and private Brazilian international airports: a two-stage DEA and Malmquist index approach," Journal of Advanced Transportation, vol. 2020, Article ID 2464869, 15 pages, 2020.

[24] L. Zhou, C. Zhou, L. Che, and B. Wang, "Spatio-temporal evolution and influencing factors of urban green development efficiency in China," Journal of Geographical Sciences, vol. 30, no. 5, pp. 724-742, 2020.

[25] H. Zhang, C. Shi, B. Wu, and Y. Yang, "Quantified relationships among the visibility, relative humidity and PM2. 5 mass concentration in Hefei city," Ecology and Environment, vol. 26, pp. 1001-1008, 2017.

[26] Z. H. Zhou, C. W. Lu, Q. W. Tan, Y. Deng, and Y. B. Bai, "Emission inventory and spatial and temporal distribution characteristics of air pollutant in Chengdu Shuangliu International Airport," Environ. Monitoring in China, vol. 34, no. 3, pp. 75-83, 2018.

[27] R. Ma, H. Luo, H. W. Wang, and T. C. Wang, "Study of evaluating high-quality economic development in Chinese regions," China Soft Science, vol. 7, pp. 60-67, 2019.

[28] Q. Huang, P. Shi, and H. Liu, "The empirical research on the measurement of high-quality regional economic development: based on Chongqing," Chongqing Social Sciences, vol. 8, no. 9, pp. 82-92, 2019.

[29] H. Fan, D. Liu, and D. Wang, "Research on efficiency and influencing factors of Chinese airports," Logistics Technology, vol. 37, no. 10, pp. 48-53, 2018. 